\title{
South African Trends in Medical Aid Coverage and Stated
}

\section{Healthcare-Seeking Preferences: 2004-14*}

\author{
Kehinde Omotoso $^{\dagger} \quad$ Steven F. Koch ${ }^{\ddagger}$
}

July 21, 2017

\begin{abstract}
Using population-weighted General Household Surveys (GHS) covering the years 2004-2014, this study examines trends in medical aid coverage and health care facility utilisation across a spectrum of socio-demographic variables. As there are few obvious patterns in the raw health variables' time series, the analysis relies upon both parametric and nonparametric regression analysis to smooth the time series in order to outline a few general trends. Over time, medical aid coverage and the general population's 'preference' for public health care decreased by $0.2 \%$ and $0.1 \%$ per year, respectively. Moreover, the probability that an individual, who is covered by a medical aid scheme, states their willingness to use public health care decreased by $44 \%$.
\end{abstract}

Keywords: Trends, Health, Repeated Surveys

\footnotetext{
${ }^{*}$ The authors would like to thank the World Health Organization for their support. All conclusions and discussions represent the views of the authors, and not necessarily the WHO.

${ }^{\dagger}$ Department of Economics, University of Pretoria, Private Bag X20, Hatfield 0028, Republic of South Africa. jewelslife2003.ko@gmail.com

${ }^{\ddagger}$ Department of Economics, University of Pretoria, Pretoria, Republic of South Africa; (0) 27-12-420-5285, (F) 27-86-691-2749. steve.koch@up.ac.za
} 


\section{Introduction}

The importance of measuring health outcomes and associated health-related behaviour for monitoring health care system performance is well-established (see Bradshaw, 2008; Bradshaw et al., 2000; Coovadia et al., 2009; Culyer and Wagstaff, 1993; Mackenbach et al., 2008). Health policies and reforms serve as significant and potent tools for improving health outcomes and health-related behaviour. In many cases, these policies are specifically targeted to improve sanitation and other social determinants of health, reduce the burden of disease, improve equitable access to basic health services and/or ensure universal health care coverage in an attempt to guarantee financial risk protection in health service utilisation. In order to understand which areas to target or which policies have been beneficial, proper and timely assessment of key health outcomes has the potential to underpin goal-setting and policy direction (see Kozhimannil et al., 2012; Rathod et al., 2014), and may represent valuable feedback for policymakers. In this research, we provide a dynamic assessment of key health indicators in South Africa, with the primary purpose of determining if there are any discernible trends.

South Africa is committed to the health of her citizens and equitable access to better health care services (Booysen, 2003). This right to health is rooted in South Africa's Constitution, which specifies that 'everyone has the right to have access to health care services, including reproductive health care (see South Africa Constitution, 1996, Section 27(1)(a)). Since 1994, which marked the end of Apartheid, the South African government has embarked on a number of health care system reforms, including restructuring and re-engineering policy to redress some of the damaging impacts of Apartheid, and creating a more coherent and unified national health system. These reforms and policies have been documented systematically (see Chopra et al., 2009; Dhai, 2011; Govender et al., 2013; Harrison, 2012; Ruff et al., 2011; Van den Heever, 2016), and prioritised in the South African government's development agenda; furthermore, an increasing share of general government expenditure is being allocated towards their implementation (Christian, 2014).

While it is obvious the South African government aims to improve health outcomes and achieve other health goals, such as equitable provision and financing, focusing on the availability and affordability of health care misses other vital issues that are relevant when describing the performance of the system. For example, from 1997 to 2006, mortality increased, although it has been declining since 2006 (Statistics South Africa, 2014b). Relatedly, the burden of disease 
associated with AIDS and TB, along with a persistently high fatality rate from injury, has been increasing. In other words, health outcomes in the country are poor, relative to total health expenditure (Bradshaw et al., 2003; Harrison, 2012). Within the context of affordability, even though some studies suggest that free primary health care, introduced in both 1994 and 1996, increased registration and facility utilisation (see Bayat and Cleaton-Jones, 2003; Harrison, 2012; McCoy and Khosa, 1996), more recent research suggests the policy did not translate as directly into increased utilisation when confronted by need, i.e., following illness or injury, (see Brink and Koch, 2015; Koch, 2017; Koch and Racine, 2016), although it appeared to improve equity related to utilisation (see Koch, 2017; Tanaka, 2014). Over time, the initial successes documented by McCoy and Khosa (1996) and Bayat and Cleaton-Jones (2003), amongst others, dissipated, given the resources available in the system (Harrison, 2012). Thus, it remains unclear, even, whether improved affordability has resulted in the improvements expected.

In many instances, policymakers are more concerned with availability and affordability than whether or not users prefer (or are willing) to utilise such publicly-provided services in the event of illness or injury, a concern that arises in Brink and Koch (2015), Koch and Racine (2016) and Koch (2017). Given policymaker concerns, the demand-side health issues are largely pushed aside, noticeably absent from policy feedback and are, therefore, insufficiently researched (see Christian, 2014; McIntyre, Thiede and Birch, 2009; Thiede et al., 2007). According to Christian (2014), this is particularly true with regard to the access dimension of the health care system. Although a number of studies (see Ataguba et al., 2011; Bradshaw, 2008; Burgard and Treiman, 2006; Christian, 2014; Gilson and McIntyre, 2007; Harris et al., 2011; Harrison, 2012; Koch, 2009; Nteta et al., 2010) have examined South Africa's health care system, little is known about demand-side behaviour, and even less is known about the dynamics of that behaviour (Bradshaw, 2008; Burger and van der Berg, 2008; Christian, 2014; Honda et al., 2015). Bradshaw (2008) examines trends in the determinants of health status using data sources, ranging from 1996 to 2007. She suggests that extreme wealth inequalities and high levels of unemployment probably play an important role in poor health outcomes in South Africa. In a similar vein, Koch (2009) examines medical aid scheme coverage rates using General Households Surveys (GHS) covering the years 2002 to 2007, and finds that coverage rates are quite low, and differ across age groups, population groups and gender over the anaylsed time period. On the other hand, Christian's (2014) investigation of the factors linked to access in the South African public health sector, using the GHS data from 2002 to 2012, reveals that although issues of acceptability and 
availability persist, equity has been achieved in terms of making public health care services more affordable, especially for the most vulnerable population groups of South African society. Our work, which is similar to these preceding studies, has a different focus. Specifically, we consider medical aid access and utilisation preference, simultaneously. In other words, we are able to address the willingness of South Africans to utilise the public healthcare system, and place that against their access to medical aid coverage. Moreover, more recent data is available, which are able to use in extending previous analyses. Therefore, our examination of the trends and determinants could shed additional light. Hence, our focus in this study is on the demandside patterns and determinants associated with access to medical aid coverage, as well as any preference for the utilisation of public health care in the event of illness or injury.

Examining trends in this set of health related variables across a range of socio-demographic variables provides a basis for measuring achievement, or otherwise, of the aforementioned goals of ensuring improved health and equitable access to better health care services. Moreover, if South Africa is to make progress towards the new Sustainable Development Goals (SDGs) and universal health care, deficiencies in the health care-related areas of the SDGs need to be identified for appropriate health policy interventions. In this study, particular attention is paid to trends and dynamics that are observed in health treatment-seeking behaviour (measured by 'stated preferences' for public health care, rather than 'revealed preferences') and health insurance (measured by medical aid scheme coverage). Post-apartheid health reforms and policies serve as the backdrop to these dynamics, although it is not possible to uncover the causal relationship between any one policy and the health trends that are observed and described, below.

\section{The Data and Methods}

Data from the GHS were analyzed using Stata 14 (StataCorp, 2015). We do not worry about causality at this stage; rather, we focus on the patterns within the data over the surveys in an effort to uncover stylised facts that might be revealed. Empirical estimates include simple percentages, some graphed for ease of reference, along with parametric (logit) and nonparametric regression (lowess). Both the logit and lowess models were used to examine the trends of medical aid coverage and preference for public or private health facility utilisation, which are all dichotomous variables. For the analysis, sample weights were used to reflect the survey 
methodology, and these weights were adjusted to account for pooling 13 years of data.

\section{$2.1 \quad$ Methods}

The graphical illustrations were based on Cleveland (1979)'s non-parametric locally weighted scatter plot smoothing, known as lowess (or Loess). Lowess does not impose a functional form on the data; rather, it allows the data to determine the shape of the relationship between two variables (Ntuli et al., 2016). Consider an unspecified empirical relationship, as in (1).

$$
H_{i}=f\left(x_{i}\right)+u_{i}
$$

In the typical analysis, $u_{i}$ is assumed to be uncorrelated with the variable of interest, $x_{i}$, and the function $f$ is to be estimated. It is estimated from weighted linear models in neighborhoods of $x_{i}$, with weights $w_{i}$.

$$
w_{i j}=\frac{c_{i}}{\lambda} d\left(\frac{x_{i}-x_{j}}{\lambda}\right)
$$

The constant $c_{i}$ normalises the weights to sum to one, $\lambda$ is a bandwidth, and $d$ is a function that treats observations farther away as being less important. In this analysis, $d$ is the tricube function.

$$
d(t)= \begin{cases}\left(1-t^{3}\right)^{3} & \text { if } t \in[0,1] \\ 0 & \text { otherwise }\end{cases}
$$

For the analysis $H$ represents the health variables (medical aid coverage and health care utilisation) preference, for selected years and socio-demographic subsets, and $x$ is age; we graphically illustrate the estimated relationship. We specify a constant bandwidth of 0.8 , implying that $80 \%$ of the sample was used to smooth each point.

Due to the binary nature of the dependent health variables of interest, the parametric estimation was based on logit model which is appropriately weighted to the population and robust to heteroskedasticity.

$$
H_{i}=L\left(\alpha T+\beta X_{i}^{\prime}\right)+v_{i} \quad T=\{2014-\text { year }\} \quad \text { year }=\{2004,2005, \ldots \ldots, 2014\}
$$

In (4), in addition to the variables already noted, $X$ denotes all controls, including age, $T$ denotes the trend in the health variables and $L$ is the functional notation for the standard 
logistic distribution. The marginal effects for the health variables are reported in Table 2. In further anlyses, we use year dummies, rather than the trend variable $T$. Those results are presented in Table A.2 in the appendix.

\subsection{Data Source}

The data used in this analysis was sourced from General Household Surveys (GHSs). The GHSs are repeated cross-sectional household surveys collected annually by the national statistical agency, Statistics South Africa (StatsSA), with new samples drawn each year (Statistics South Africa, 2014a). ${ }^{1}$ The annual survey collects a range of demographic and socio-economic information on households and individuals across the country's nine provinces. Survey questions relate to housing services, social services, socio-demographics, labour markets, and household tourism activities. Most pertinent to this analysis, there is a short series of health-related questions covering preference for the utilisation of public or private health services in the event of illness, and access to medical aid coverage, amongst others. ${ }^{2}$

Each year, the sample includes approximately 30,000 households, and that sample follows a multi-stage stratified design, such that each is representative at both the national and provincial levels within any year; population weights are available in the surveys for both households and individuals. ${ }^{3}$ To account for the different survey designs among the datasets used in this paper, we use the adjusted survey weights provided by StatsSA, but modify them for use across multiple surveys.

As suggested earlier, this study utilized thirteen sequential survey waves (2002-2014). ${ }^{4}$ Information collected in the GHS that is consistent across all the surveys and relevant for the analysis includes: age; gender; race (African Black, Coloured, Asian/Indian and White); marital status

\footnotetext{
${ }^{1}$ The GHS datasets are publicly available and could be accessed from https://www.datafirst.uct.ac.za/dataportal/index.php/catalog/526/get_microdata

${ }^{2}$ The question is phrased not with respect to the type of facility that was used following a particular illness episode; rather the question was phrased with respect to the facility that would be used if an illness event was observed in the household, i.e., it relates to stated preferences, rather than revealed preferences. The earlier question was part of the GHS up to 2008, while the latter started in 2004 and was asked in subsequent surveys.

${ }^{3}$ Combining the data across the years does require care, due to differences in the underlying sample frame. For the 2002 to 2011 GHS datasets, demarcations for the 2001 census served as the basis for sampling design and enumeration areas, although there was a need to adjust due to provincial boundary changes in 2006 and 2011. The 2012-2014 GHS datasets incorporate the 2011 census. A two-stage weighting procedure was applied to the GHS datasets. Weighting and benchmarking were also adjusted for the provincial boundaries that came into effect in 2006 and 2011, making the data from GHS 2002 to GHS 2014 comparable (Statistics South Africa, 2014a). For details on the derivation of the GHS weights and other adjustments made in the datasets, see respective survey metadata files and technical notes' sections of the statistical release https://www.datafirst.uct.ac.za/dataportal/index.php/catalog

${ }^{4}$ The datasets were cleaned by excluding "don't know's", as well as other unspecified responses in variables relevant for our analysis
} 
(married, widow/widower, divorced/separated and single); employment status; highest level of education completed (no schooling, less than diploma, diploma/certificate, university degree, and postgraduate degree); province; urban/rural setting; access to medical aid coverage and health facilities utilisation/preference.

In the surveys, medical aid coverage status was measured by asking respondents whether they were currently covered by a medical aid or benefit scheme or other private health insurance at the time of the survey. Those answering in the affirmative are classified as medically insured, while those answering in the negative were categorized as uninsured. As noted above, we base facility utilisation on stated preferences. Specifically, respondents (from 2004-2014) were asked if they would seek care in either a public or private health facility in times of illness or injury. In this research, we refer to the responses received as a 'preference' for public or private care, even though it does not represent revealed preferences. ${ }^{5}$ In addition to questions about health facility preference, there are a number of questions related to illness and disability. However, neither disabilities nor illnesses are incorporated in the following analysis. A number of other questions were also asked in these surveys that are related to health outcomes. For example, reasons for not consulting any health worker, if ill during the past month, were also requested in early surveys, through 2008; since they were not available for a longer period of time, these data were also ignored in the analysis.

Despite consistency in the phrasing of many questions across the surveys, the potential for inconsistency in responses still exists. For example, surveyors could emphasise different sets of questions or responses in any survey or household; furthermore, surveyors or data capturers could miscode responses. Errors could also arise because of misunderstanding of the survey questions, or uncertainty about other household members or even deliberate distortion of responses (Baltagi, 2008). ${ }^{6}$ As long as the errors are randomly distributed over time and within surveys, the effects on what is reported below should be minimal; however, non-random errors, such as deliberate distortion or selective non-response, could lead to over (or under) reporting of certain events, which could yield higher (or lower) trends than actually occurred. Although it is not possible to address such concerns, we take cognizance of their existence during the analysis.

\footnotetext{
${ }^{5}$ In reality, attendance decisions are affected by availability and cost, as well as views on quality; thus, responses do not represent actual preferences over the ownership of the health facility.

${ }^{6}$ It should be understood that the surveys are completed by a responsible adult household member who is available, rather than by everyone. Thus, simple errors could arise from the responsible adult not knowing all of the information.
} 


\subsection{Data Summary}

Before undertaking the analysis, we report summary statistics for the main variables. These are presented in Table 1, and cover the years 2002-2014. These are not separated by year, although such information can be requested from the authors. The main outcome variables, though, are presented across the years in Table A.1, and illustrated in Figure 1.

As can be seen in Figure 1, there is no obvious increasing or decreasing pattern in medical aid coverage. Instead, there are peaks and valleys. Medical aid coverage peaked in 2013, while the trough in medical aid coverage occurred in 2005. The reversal of the drop in coverage up to 2005 can be attributed to the introduction of the Government Employees Medical scheme (GEMS), which extended coverage to previously uninsured government employees starting in 2005 (see Govender et al., 2013; Government Employees Medical Scheme, 2012).

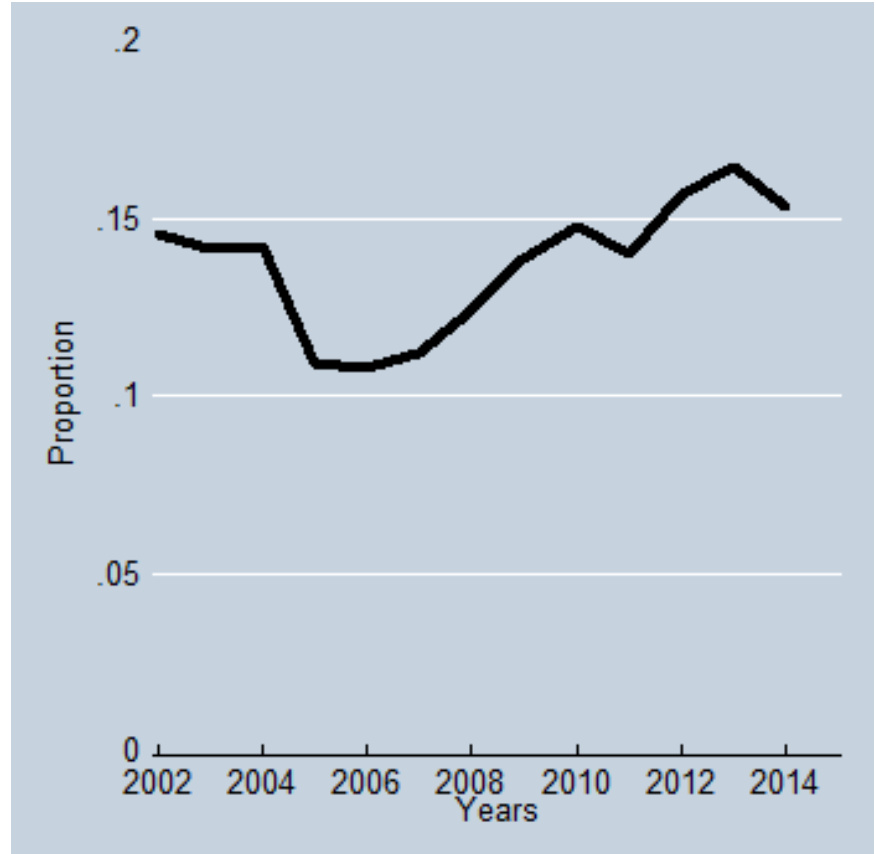

Figure 1: Trends in medical aid coverage in South Africa, GHS 2002-2014. Proportions are illustrated for each year of the GHS.

Table 1 presents sub-sample proportions across a wide-range of categorical variables. The sub-samples are those having medical aid coverage and those who would (prefer to) use a public health facility, if they were ill. ${ }^{7}$

\footnotetext{
${ }^{7}$ In the early years of the GHS, respondents would be asked questions focused more on revealed preferences. Specifically, if an individual reported an illness/injury, they would be asked if care was sought for the illness/injury. In those years, the number observed utilising public health facilities would necessarily be lower than the number reported ill. In 2004, the focus changed to scenario preferences - what would they do if they were ill/injured and, therefore, the relative number of observations switched across the sub-samples.
} 
Table 1: Descriptive statistics, data from the 2002-2014 General Household Surveys.

\begin{tabular}{|c|c|c|c|c|}
\hline \multirow[b]{2}{*}{ Variables } & \multicolumn{2}{|c|}{ Public health facility } & \multicolumn{2}{|c|}{ Medical aid coverage } \\
\hline & Obs. & $\%$ & Obs. & $\%$ \\
\hline \multicolumn{5}{|l|}{ Age } \\
\hline Less than 6 years & 108,833 & 12.8 & 16,113 & 9.3 \\
\hline $6-17$ years & 228,846 & 26.9 & 37,878 & 21.7 \\
\hline $18-30$ years & 202,263 & 23.8 & 29,794 & 17.1 \\
\hline $31-45$ years & 141,501 & 16.6 & 44,102 & 25.3 \\
\hline $46-64$ years & 117,746 & 13.8 & 36,249 & 20.8 \\
\hline 65 years + & 51,585 & 6.1 & 10,042 & 5.8 \\
\hline \multicolumn{5}{|l|}{ Race } \\
\hline African/Black & 739,353 & 86.9 & 83,508 & 47.9 \\
\hline Coloured & 91,810 & 10.8 & 24,477 & 14.1 \\
\hline Indian/Asian & 9,777 & 1.1 & 9,519 & 5.5 \\
\hline White & 9,834 & 1.2 & 56,674 & 32.5 \\
\hline \multicolumn{5}{|l|}{ Gender } \\
\hline Male & 394,036 & 46.3 & 84,332 & 48.4 \\
\hline Female & 456,738 & 53.7 & 89,846 & 51.6 \\
\hline \multicolumn{5}{|l|}{ Marital Status } \\
\hline Married & 185,726 & 21.8 & 78,090 & 44.9 \\
\hline Widow/Widower & 50,764 & 6 & 6,308 & 3.6 \\
\hline Divorced or Separated & 14,882 & 1.8 & 4,243 & 2.4 \\
\hline Single & 598,924 & 70.4 & 85,424 & 49.1 \\
\hline \multicolumn{5}{|l|}{ Education } \\
\hline No Schooling & 172,926 & 20.5 & 17,932 & 10.4 \\
\hline Less than Diploma & 651,719 & 77.4 & 11,3194 & 65.6 \\
\hline Diploma/Certificate & 13,333 & 1.6 & 21,924 & 12.7 \\
\hline Honours/Degree & 3,798 & 0.5 & 16,555 & 9.6 \\
\hline Postgraduate & 289 & 0.001 & 2,848 & 1.7 \\
\hline \multicolumn{5}{|l|}{ Employment status } \\
\hline Employed & 132,623 & 15.6 & 66,525 & 38.2 \\
\hline Not Employed & 718,151 & 84.4 & 107,653 & 61.8 \\
\hline \multicolumn{5}{|l|}{ Metropolitan status } \\
\hline Rural & 433,448 & 50.9 & 27,767 & 15.9 \\
\hline Urban & 417,326 & 49.1 & 146,411 & 84.1 \\
\hline \multicolumn{5}{|l|}{ Medical aid coverage } \\
\hline Covered & 30,051 & 3.55 & 174,178 & 13.68 \\
\hline Not covered & 817,444 & 96.45 & $1,098,833$ & 86.32 \\
\hline
\end{tabular}

\footnotetext{
Descriptive statistics for two sub-samples (those having medical aid coverage and those with a "preference' for public health care, when ill) taken from the pooled GHS data 2002-2014. Percentages are reported within each sub-sample
}

Given the structure of the sub-samples, relative comparisons are not particularly insightful. Instead, the descriptive statistics provide some information regarding the relative proportions within a sub-sample. Therefore, we point out only a few within sub-sample comparisons. In particular, we see that the populace is relatively uneducated, is not working and is not covered by a medical aid scheme; however, we should keep in mind that our sub-samples include children who are currently in school, and, therefore, have not completed their schooling and are not working. Relatively speaking, within the public health facility 'preferred' sub-sample, there are more observations (the data is not weighted here) in the 6-17 years of age bracket, African/blacks, female, single individuals, less educated, unemployed, those not covered with medical aid, and rural dwellers. With respect to medical aid coverage, it is highest amongst those in prime working age, 31-45 years, while it is primarily an urban phenomenon. The 
stylised fact that relatively few of those covered are employed presumably derives from policies that cover children and spouses.

\section{A Description of the Trends}

We continue with the analysis, breaking down the trends in our two primary outcome variables across a number of socio-economic categories. The age distributions of the health variables are also illustrated across selected years and a range of socio-demographic characteristics. Recent studies suggest that disparities in self-assessed health, disability, health facility utilisation and heath-related behaviour do differ by age (Horner-Johnson et al., 2013; Wandera et al., 2015). Given that the NHI policy paper states that health insurance coverage will be provided to all citizens and permanent residents irrespective of age and employment, a number of studies have highlighted the importance of age structure and gender in examining health insurance coverage in South Africa (see McLeod, 2007, 2009a,b, 2012).

\subsection{Medical aid coverage}

In the South African context, one of the key components of health indicators, in our view, is medical aid coverage. Thus, we begin our analysis with this component; see Figure 2.

We consider medical aid coverage across the survey years, although illustrating only some of the years in order to keep the illustrations readable. For reasons previously mentioned, we focus on medical aid coverage by age. As shown in Figure 2, the age distribution of medical scheme coverage across the surveys is quite stable. Coverage peaks around the age of 60 in each of the survey years illustrated, and is lowest for the oldest individuals. As expected, given Figure 1, coverage is relatively higher in 2014 than it was in 2002. There is a noticeable inverted $U$-shape to the age distribution of medical aid coverage. Medical aid coverage increased steadily among young adults over the study periods, a time period that matches attachment to the labour force.

A comparison of the age distribution of medical aid coverage across socio-demographic variables was also illustrated; see Figure 3. Since Gauteng is the richest province in the country and contains a greater proportion of formally employed adults, medical coverage is highest there.

For similar reasons, urbanites, men and white South Africans are more likely to have access to a medical aid scheme than their counterparts. As was the case, generally, within each survey, medical aid coverage peaks around the age of 60 across location, as well as for men and women. 


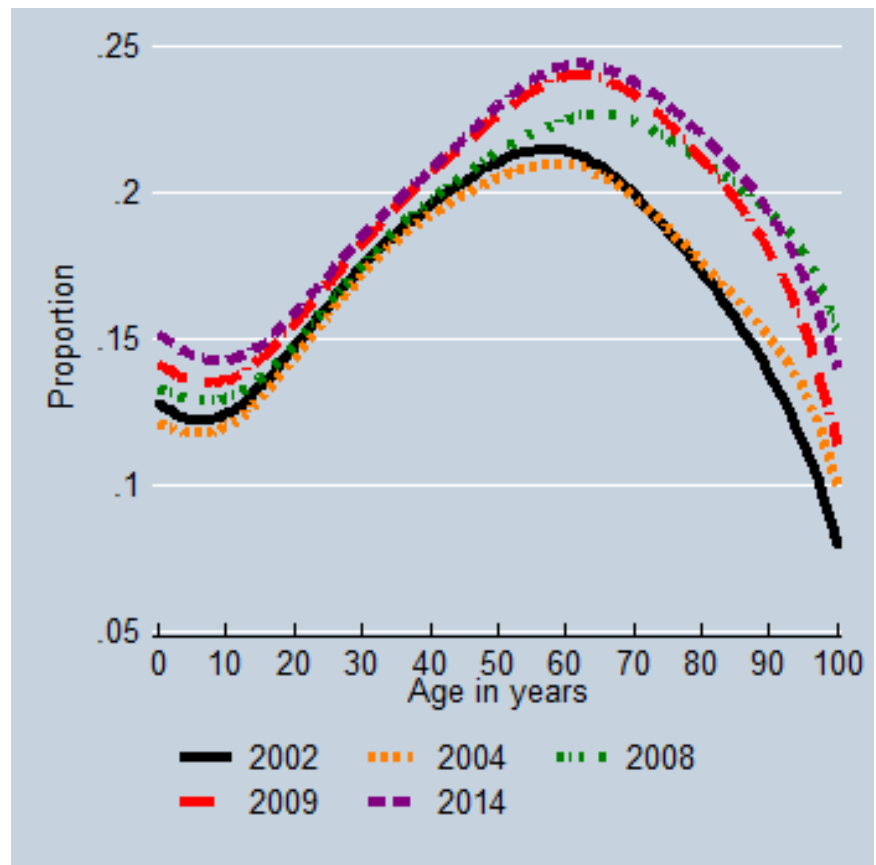

Figure 2: The age distribution of medical aid insurance in South Africa for selected years from the GHS 2002-2014. Proportions are for those who reported having medical aid coverage as at the date of the survey at any age. The illustrations are taken from lowess nonparametric regressions of medical aid coverage status on age in each year; thus, the pattern is smoothed.

However, the peak occurs at lower ages within the African black and coloured populations in South Africa, while coverage appears highest amongst the young in the Indian population.

\subsection{Health facility preference}

Given South Africa's health sector history (see Coovadia et al., 2009), as well as the differences in usage reported in previous research, it is no surprise that public health care is more likely to be 'preferred' to private health care (see Gilson and McIntyre, 2007), keeping in mind that these preferences are not revealed. However, from 2006, there has been a steady increase in the preference for private health care, possibly attributable to the introduction of GEMS (Govender et al., 2013). See Figure 4 for details.

Preferences are further broken down by age, across different surveys; as before, we do not illustrate all survey years, in order to keep the illustrations presentable. Figure 5 presents these preferences; the left panel contains public care preferences, while the right panel focuses on the private sector. As should be the case, the two panels are mirror images. However, what was not expected was the rather distinct differences by age, even though public care preferences remain the norm. A preference for public care is lowest (highest) for those aged near 60 years, and is higher (lower) for ages above and below that. The $U$-shape (inverse $U$-shape) depicted 


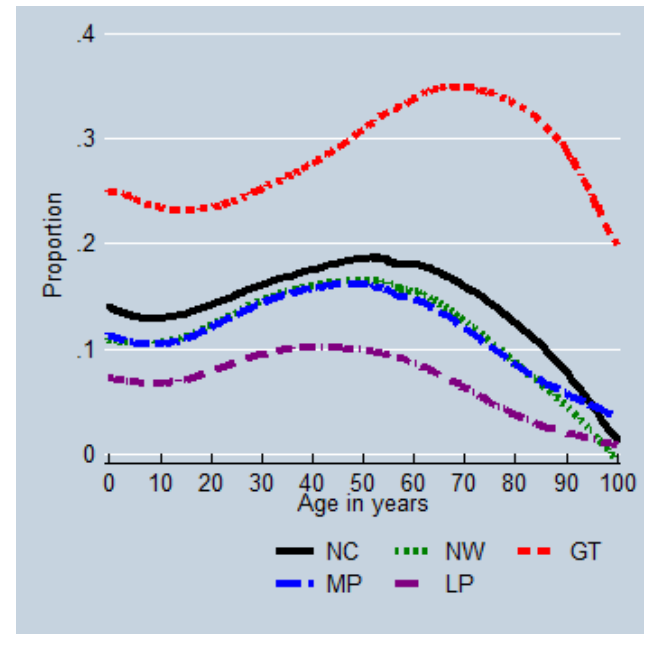

(a) Selected provinces

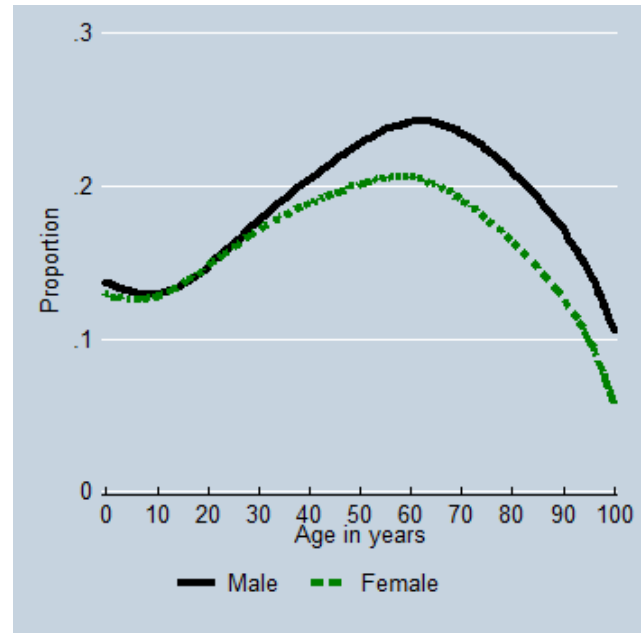

(c) Gender

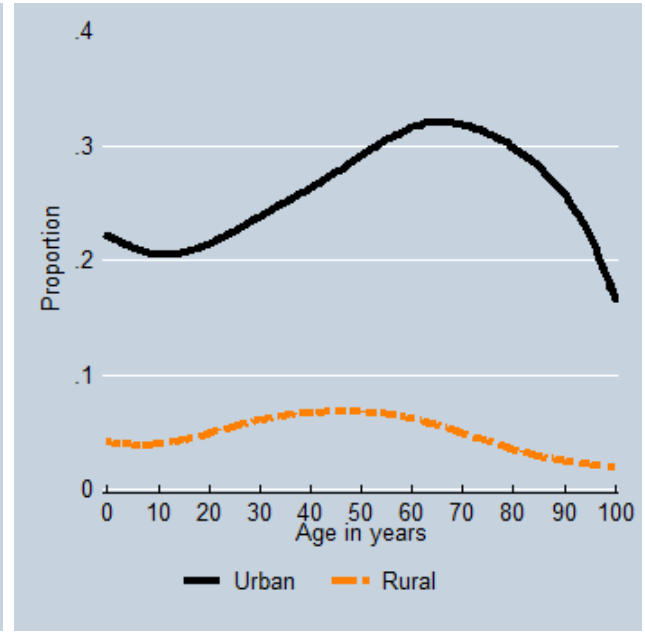

(b) Rural/urban setting

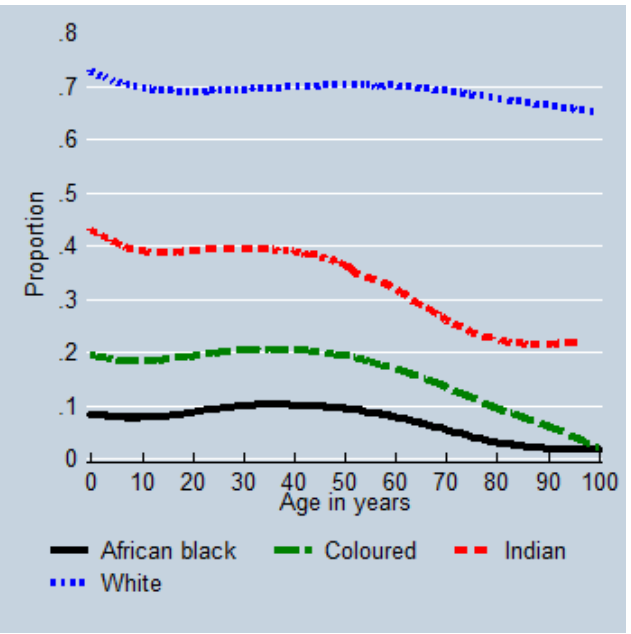

(d) Race

Figure 3: The age distribution of medical aid insurance in South Africa from the GHS 20022014. The distribution is separated by province, rural/urban locale, gender and race group. Proportions are for those who reported having medical aid coverage as at the date of the survey. The illustrations are taken from lowess nonparametric regressions of medical aid coverage status on age in each year; thus, the pattern is smoothed.

suggests that those near the end of their working lives either place relatively greater trust in the private sector to cope with the illnesses/injuries they expect to encounter or have greater access to the private health care sector.

When comparisons are made across race and gender, we uncover both similarities and differences with respect to the facility owner; see Figure 5 for the comparisons. Firstly, the age-based $U$-shape to public and private care preferences are easily observed for men and women, while the troughs (peaks) occur at an age near 60. Secondly, amongst males, there is a relatively strong preference for the private sector, presumably because they have greater access to medical aid schemes. Thirdly, however, the pattern is not as easily observed across race groups. Although the $U$ remains, the peaks (troughs) do not occur near age 60 for non-white population 


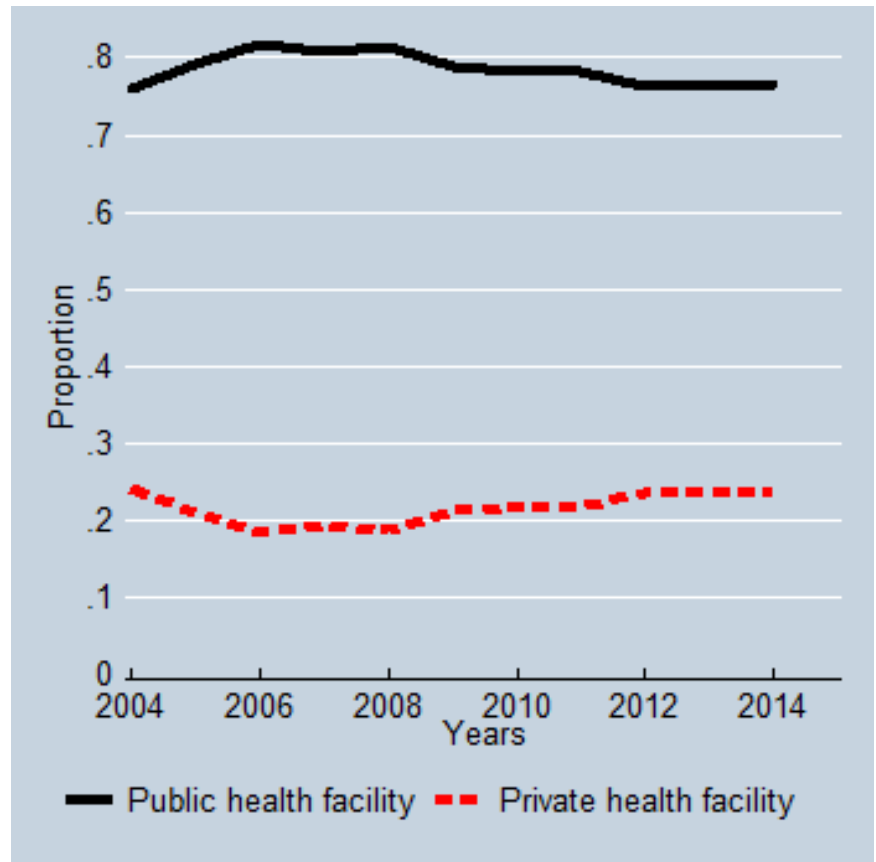

Figure 4: Preferences for private and public health care, if ill, in South Africa. Data sources from the GHS 2004-2014. Proportions are for those who utilise either public or private health care facility in the event of illness/injury.

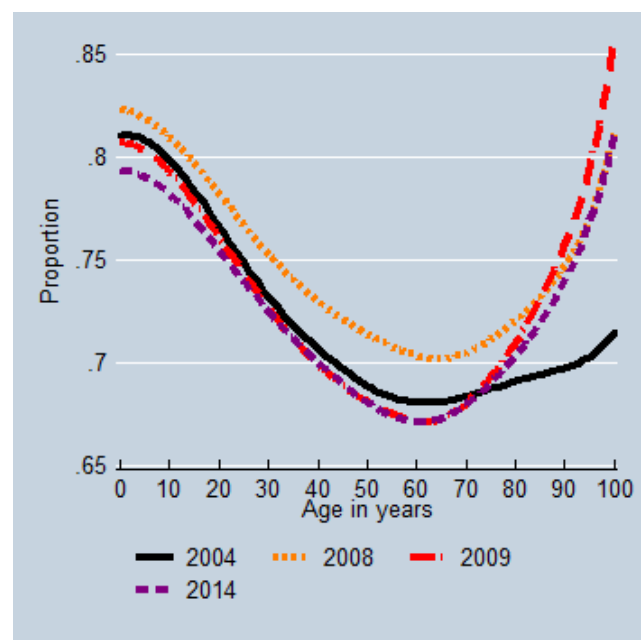

(a) Public health facility

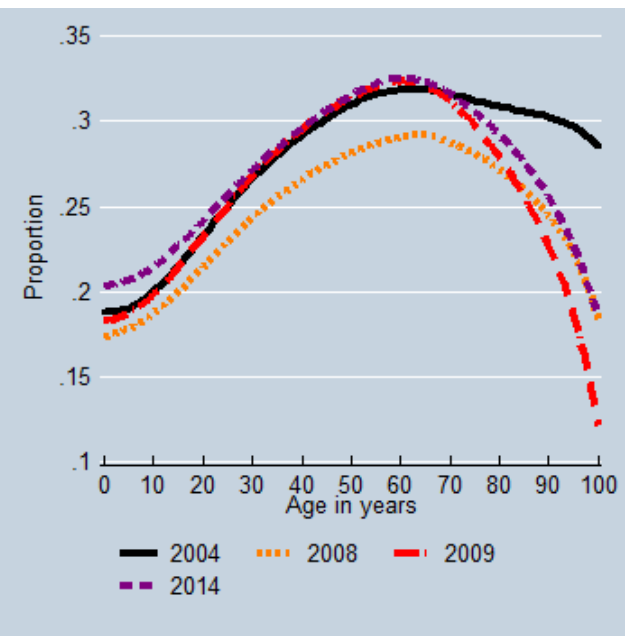

(b) Private health facility

Figure 5: The age distribution of public and private health care facility utilisation in South Africa for selected years from the GHS 2004-2014. Proportions are for those who utilised either public or private health care facility at any age. The illustrations are taken from lowess nonparametric regressions of each of public and private health care facility on age in each year; thus, the pattern is smoothed.

groups. Instead, for African blacks and coloureds, they are closer to age 40, which is also in line with their access to medical aid coverage. 


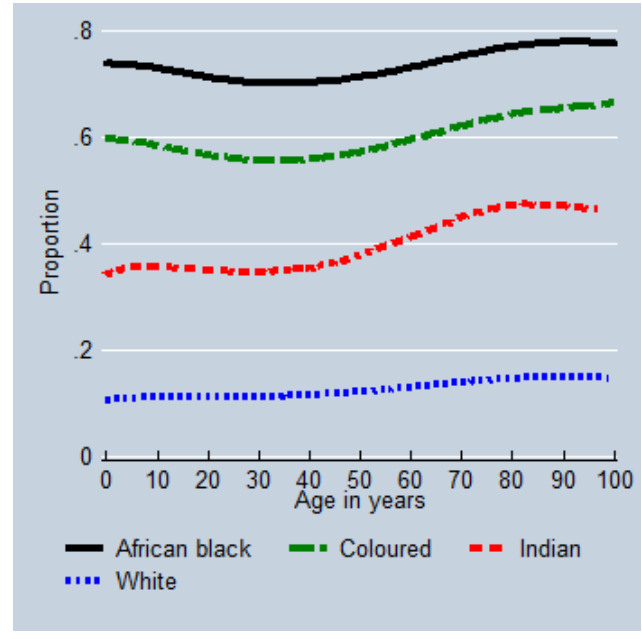

(a) Public Preference: Race

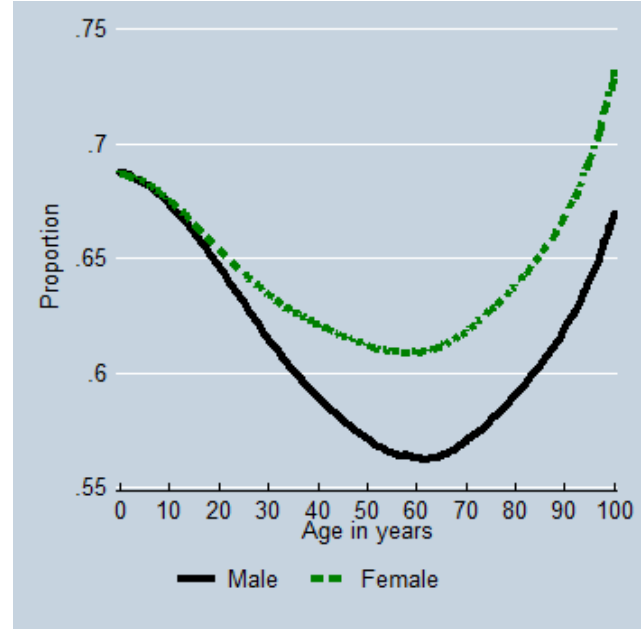

(c) Public Preference: Gender

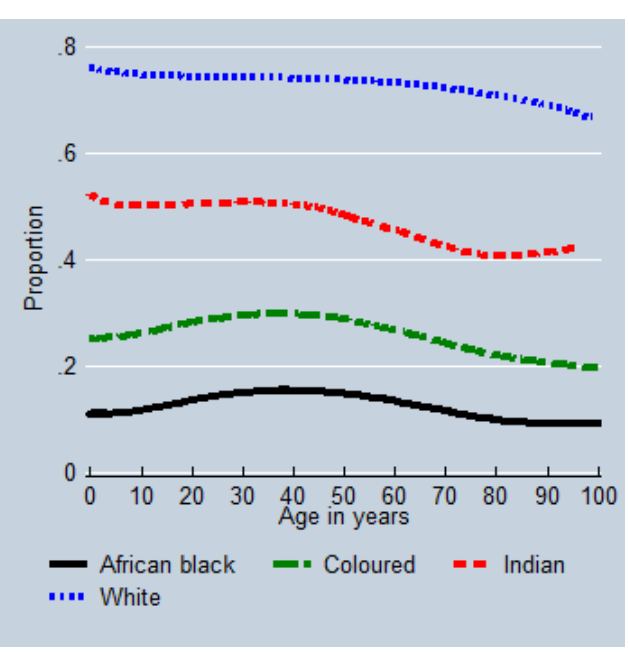

(b) Private Preference: Race

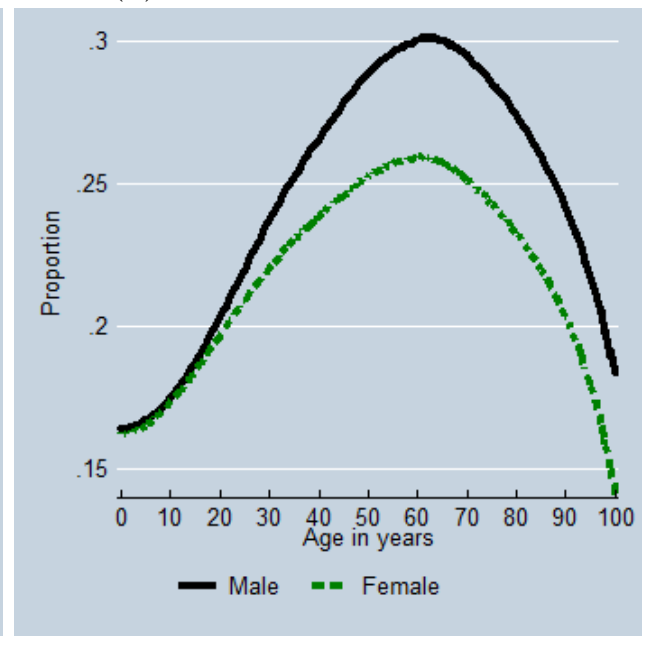

(d) Private Preference: Gender

Figure 6: Preferences for private and public health care, if ill, in South Africa. The illustrations are separate for race (top-left and top-right) and gender (bottom-left and bottom-right). Proportions are for the racial groups and gender (male/female) at any age. The illustrations are taken from lowess nonparametric regressions of the above variables on age in each year; thus, the patterns are smoothed.

\section{Estimating the Trends}

As the preceding descriptive analysis suggests, there are potential socio-economic differences in key health variables, and those may not have been consistent over time. However, that analysis was fairly limited, in that it was primarily bivariate. For that reason, the previous analysis was extended to account for multiple control variables at once. Specifically, we examine the determinants of our two key health measures, controlling for age, race, gender, marital status, province and rural/urban setting. Estimation was based on logit, and the marginal effects from the logit are included in Table $2 .^{8}$

\footnotetext{
${ }^{8}$ The actual regression estimates for each year are presented in Table A.2. Estimation was weighted to the population in each year.
} 
Recall, the primary purpose of the analysis was to determine if there are any discernible trends in health indicators in South Africa. According to the results, access to medical aid coverage and the general population's preference for choosing a public health care facility (if they were ill) fell. Moreover, the probability of preferring public health care in the event of illness/injury, as well as being a member of a medical aid scheme, are decreasing over the time period. The decreases are around $0.1 \%$ and $0.2 \%$ per year, respectively. All of these trends are statistically significant.

Table 2: Marginal Effects for Public Health Facility Utilisation and Medical Aid Coverage

\begin{tabular}{|c|c|c|c|c|}
\hline \multirow{2}{*}{$\begin{array}{l}\text { Variables } \\
\text { Trend (2004-2014) per annum }\end{array}$} & \multicolumn{2}{|c|}{ Public health facility } & \multicolumn{2}{|c|}{ Medical aid coverage } \\
\hline & $-0.001^{* * *}$ & $(0.000)$ & $-0.002^{* * *}$ & $(0.000)$ \\
\hline Age & $0.002^{* * *}$ & $(0.000)$ & $-0.006^{* * *}$ & $(0.000)$ \\
\hline Age-squared & $-0.000^{* * *}$ & $(0.000)$ & $0.000^{* * *}$ & $(0.000)$ \\
\hline African/Black & $0.473^{* * *}$ & $(0.004)$ & $-0.479^{* * *}$ & $(0.003)$ \\
\hline Coloured & $0.396^{* * *}$ & $(0.005)$ & $-0.392^{* * *}$ & $(0.004)$ \\
\hline Indian/Asian & $0.181^{* * *}$ & $(0.007)$ & $-0.295^{* * *}$ & $(0.006)$ \\
\hline Gender (female=1) & $0.009^{* * *}$ & $(0.001)$ & $0.004^{* * *}$ & $(0.001)$ \\
\hline Married & $-0.026^{* * *}$ & $(0.002)$ & $0.081^{* * *}$ & $(0.002)$ \\
\hline Widow/widower & 0.007 & $(0.004)$ & $0.006^{*}$ & $(0.003)$ \\
\hline Divorce or separated & 0.003 & $(0.005)$ & $0.017^{* * *}$ & $(0.003)$ \\
\hline Eastern Cape & $0.070^{* * *}$ & $(0.003)$ & $0.021^{* * *}$ & $(0.002)$ \\
\hline Northern Cape & $0.101^{* * *}$ & $(0.003)$ & $0.004^{* *}$ & $(0.001)$ \\
\hline Free State & $-0.045^{* * *}$ & $(0.003)$ & $0.022^{* * *}$ & $(0.002)$ \\
\hline Kwazulu/Natal & $0.090^{* * *}$ & $(0.003)$ & $0.022^{* * *}$ & $(0.002)$ \\
\hline North-West & $-0.008^{*}$ & $(0.004)$ & $0.053^{* * *}$ & $(0.002)$ \\
\hline Gauteng & $0.021^{* * *}$ & $(0.003)$ & $0.032^{* * *}$ & $(0.002)$ \\
\hline Mpumalanga & -0.005 & $(0.003)$ & $0.052^{* * *}$ & $(0.002)$ \\
\hline Limpopo & $0.087^{* * *}$ & $(0.003)$ & $0.047^{* * *}$ & $(0.002)$ \\
\hline Less than diploma/certificate & $-0.026^{* * *}$ & $(0.002)$ & $0.040^{* * *}$ & $(0.001)$ \\
\hline Diploma/certificate & $-0.236^{* * *}$ & $(0.006)$ & $0.342^{* * *}$ & $(0.005)$ \\
\hline Honours/degree & $-0.303^{* * *}$ & $(0.009)$ & $0.494^{* * *}$ & $(0.007)$ \\
\hline Postgraduate degree & $-0.331^{* * *}$ & $(0.031)$ & $0.481^{* * *}$ & $(0.027)$ \\
\hline Employment status (employed=1) & $-0.056^{* * *}$ & $(0.002)$ & $0.049^{* * *}$ & $(0.001)$ \\
\hline Metropolitan status (urban=1) & $-0.114^{* * *}$ & $(0.002)$ & $0.113^{* * *}$ & $(0.001)$ \\
\hline Medical aid (coverage $=1$ ) & $-0.440^{* * *}$ & $(0.002)$ & & \\
\hline Observation & $1,064,453$ & & $1,064,453$ & \\
\hline
\end{tabular}


Marginal Effects for Public Health Facility Utilisation and Medical Aid Coverage: Continued

\begin{tabular}{llc}
\hline \hline & Public health facility & Medical aid coverage \\
\hline$R^{2}$ & 0.036 & 0.29 \\
\hline \hline
\end{tabular}

Standard errors in parentheses

${ }^{*} p<0.05,{ }^{* *} p<0.01,{ }^{* *} p<0.001$

Notes: This table contains marginal effects preference of public health facility utilisation, and medical aid coverage. The marginal effects are separate for preference of public health facility utilisation (left), and medical aid coverage (right). Marginal effect is a measure of the instantaneous effect that a change in an explanatory variable has on the predicted probability of the outcome variable (in this case, our outcome variables are preference of public health facility utilisation and medical aid coverage), when the other covariates are held constant.

With respect to preferences for the use of a public health facility in the event of an illness/injury, we find that females are $0.9 \%$ more likely to say would use public health care than males. Furthermore, older people are less likely to use public heath services; they are the reference group, while younger people use public health care $0.2 \%$ more often. As expected, those residing in urban areas use public health care $11.4 \%$ less often than those residing in rural areas. We also find that the formally educated are less likely to utilise public health care than those with no formal education (the reference group). Finally, according to the age polynomial in the analysis, there is evidence of a $U$-shape in the preference for public health facilities, once these additional controls have been included.

Furthermore, we find that medical aid coverage is associated with a $44 \%$ lower probability of preferring to utilise public health care in the event of illness/injury; there are also large race and educational differences, many of which can be tied to the pattern of income and wealth in the country. African blacks are $47.3 \%$ more likely to prefer public health facilities for medical treatment, compared to the white population, while married people $(2.6 \%)$ are less likely to prefer a public health facility than single individuals. Females, compared to males, are $0.9 \%$ more likely to prefer to utilise public health care when ill. Furthermore, preferences for the employed are $5.6 \%$ lower than the unemployed, when it comes to potentially seeking care at a public facility, when ill. In terms of education, public care utilisation preferences range from 24-33\% lower amongst the formally educated, compared to those not formally educated. Finally, pereferences in urban area are in favour of private facilities, as those in urban areas have an $11.4 \%$ lower probability of stating a willingness to seek medical treatment at a public health 
care facility, in times of illness/injury. When compared with the Western Cape, the likelihood of utilising public health care is higher in Eastern Cape, Northern Cape, KwaZulu-Natal, Gauteng, and Limpopo.

As implied in the earlier analysis, medical aid coverage mirrors public health care preferences, at least partly due to the ability to pay for private health care through third party payees. African blacks coverage probabilities are nearly $50 \%$ lower than Whites, while married individual coverage rates are $8.1 \%$ higher than for singles. Men have higher coverage rates than women, by approximately $0.4 \%$. The probability of coverage is also higher amongst urbanites, the employed, and the formally educated. Urban area coverage is higher by $11.3 \%$; for the employed it is $4.9 \%$ higher; coverage rates are between $34-50 \%$ higher for the formally educated than it is for the uneducated.

\section{Discussion and Conclusion}

The preceding analysis has taken data from the General Household Surveys focusing on the years 2004-2014. The data has been pooled, weighted to the population, and used for a trend analysis of medical aid coverage and preferences for public care (loosely defined). The analysis is primarily descriptive in nature, although one could argue that the control variables are primarily exogenous, with the exception of location. For that reason, we have not included variables such as income or expenditure, which could both affect health and be affected by health.

Although the primary purpose of the analysis was to estimate trends in our key variables, a number of additional controls were included in the analysis, and are found to be statistically significant determinants of health care preferences and access to medical aid schemes (or health insurance) in South Africa. Strong evidence of a time trend was uncovered in the analysis, with preferences for public health facilities and medical aid coverage decreasing, on average, by $0.1 \%$ and $0.2 \%$ annually respectively. The decrease in medical aid coverage is somewhat surprising given the implementation of the Government Employees Medical Scheme, which did open-up medical aid coverage to a much larger set of formally employed individuals in the country. However, the decrease could also relate to the fact that primary health care sector has been re-engineered (and improved), while the direct costs of accessing primary health care have decreased due in part to user fee policy changes in 1994 and 1996.

Although the decrease in coverage does signal the need to think carefully about health 
care financing, keeping in mind the observed decrease in public health care preferences. These two trends - which operate together in this analysis - suggest that South Africans are not enamoured by the public health sector, even though they cannot afford the private sector. Thus, any implementation of a National Health Insurance (NHI) Scheme needs to address both the declining medical aid coverage rates - a national health insurance program is designed specifically to engender coverage - and the reduced preference for the provision of health care by the public sector. To a large extent, the feasibility of the successful implementation of the proposed NHI depends on the improvement of the public health care services; otherwise, private services could easily be overrun. Our recommendation, in this regard, will be in line with the suggestion of McIntyre, Goudge, Harris, Nxumalo and Nkos (2009) on the need to improve public perceptions of public health services. In order to do so, the government would need to improve the quality of public health services, and possibly consider additional incentives to encourage the utilisation of public health facilities.

More worryingly, despite policies that have been targeted the poor - primarily children, female, non-whites and those living in rural areas - the overall picture does not suggest much change over the time period. It is these people who mostly suffer from poor health, state that they prefer to use the public sector and do not have access to medical aid schemes. However, we note that further analysis within these and other sub-groups of the population are warranted. Our results, which are in line with other studies (see Bradshaw, 2008; Bradshaw et al., 2000), suggest the need for more policy engagement with respect to health in South Africa. While Primary Health Care reforms and other policies have impacted outcomes (see Harrison, 2012), further strengthening the promotive component of health care will likely lead to further improvements in health. Since access to appropriate health care services is fundamental to the choices that are made with respect to health facility in the event of illness or injury, and it is a feature of the constitution - "everyone has the right to have access to health care services, including reproductive health care" (see South Africa Constitution, 1996, Section 27(1)(a)) ensuring access remains a policy priority. 


\section{References}

Ataguba, J. E., Akazili, J. and McIntyre, D. (2011), 'Socioeconomic-related health inequality in South Africa: Evidence from General Household Surveys', International Journal for Equity in Health 10(48), 1-10.

Baltagi, B. (2008), Econometric analysis of panel data, John Wiley \& Sons.

Bayat, A. and Cleaton-Jones, P. (2003), 'Dental clinic attendance in Soweto, South Africa, before and after the introduction of free primary dental services', Community Dentistry and Oral Epidemiology 31(2), 105-110.

Booysen, F. (2003), 'Urban-rural inequalities in health care delivery in South Africa', Development Southern Africa 20(5), 659-673.

Bradshaw, D. (2008), 'Determinants of health and their trends: Primary health care: in context', South African Health Review 2008(1), 51-69.

Bradshaw, D., Groenewald, P., Laubscher, R., Nannan, N., Nojilana, B., Norman, R., Pieterse, D., Schneider, M., Bourne, D. E., Timæus, I. M. et al. (2003), 'Initial burden of disease estimates for South Africa, 2000', South African Medical Journal 93(9), 682-688.

Bradshaw, D., Masiteng, K. and Nannan, N. (2000), 'Health status and determinants', South African Health Review 2000(1), 89-124.

Brink, A. S. and Koch, S. F. (2015), 'User fee abolition in South Africa in 1994 and 1996: Difference-in-differences', Development Southern Africa 32(2), 170-192.

Burgard, S. A. and Treiman, D. J. (2006), 'Trends and racial differences in infant mortality in South Africa', Social Science $\& 3$ Medicine 62(5), 1126-1137.

Burger, R. and van der Berg, S. (2008), 'How Well Is the South African Public Health Care System Serving Its People?', Risk and opportunity.

Chopra, M., Lawn, J. E., Sanders, D., Barron, P., Karim, S. S. A., Bradshaw, D., Jewkes, R., Karim, Q. A., Flisher, A. J., Mayosi, B. M. et al. (2009), 'Achieving the health Millennium Development Goals for South Africa: Challenges and priorities', The Lancet 374(9694), 10231031. 
Christian, C. S. (2014), 'Access in the South African public health system: Factors that influenced access to health care in the South African public sector during the last decade', University of Western Cape, South Africa.

Cleveland, W. S. (1979), 'Robust locally weighted regression and smoothing scatterplots', Journal of the American Statistical Association 74(368), 829-836.

Coovadia, H., Jewkes, R., Barron, P., Sanders, D. and McIntyre, D. (2009), 'The health and health system of South Africa: Historical roots of current public health challenges', The Lancet 374(9692), 817-834.

Culyer, A. J. and Wagstaff, A. (1993), 'Equity and equality in health and health care', Journal of Health Economics 12(4), 431-457.

Dhai, A. (2011), 'Healthcare reform in South Africa: A step in the direction of social justice: editorial', South African Journal of Bioethics and Law 4(2), 48-49.

Gilson, L. and McIntyre, D. (2007), 'Post-Apartheid challenges: Household access and use of health care in South Africa', International Journal of Health Services 37(4), 673-691.

Govender, V., Chersich, M. F., Harris, B., Alaba, O., Ataguba, J. E., Nxumalo, N. and Goudge, J. (2013), 'Moving towards universal coverage in South Africa? Lessons from a voluntary government insurance scheme', Global Health Action 6, 109-118.

URL: http://hdl.handle.net/1854/LU-3162700

Government Employees Medical Scheme (2012), 'GEMS and its performance', 16 May 2012 Portfolio Committee on Public Service and Administration.

Harris, B., Goudge, J., Ataguba, J. E., McIntyre, D., Nxumalo, N., Jikwana, S. and Chersich, M. (2011), 'Inequities in access to health care in South Africa', Journal of Public Health Policy 32(1), 102-123.

Harrison, D. (2012), 'An overview of health and health care in South Africa 1994-2010: Priorities, progress and prospects for new gains; 2009', Washington, DC: Henry J Kaiser Family Foundation.

Honda, A., Ryan, M., van Niekerk, R. and McIntyre, D. (2015), 'Improving the public health sector in South Africa: Eliciting public preferences using a discrete choice experiment', Health Policy and Planning 30(5), 600-611. 
Horner-Johnson, W., Dobbertin, K., Lee, J. C., Andresen, E. M. et al. (2013), 'Disparities in chronic conditions and health status by type of disability', Disability and Health Journal 6(4), 280-286.

Koch, S. F. (2009), 'Equity in private health insurance coverage in South Africa: 2002-2007', University of Pretoria, Department of Economics Working Paper: 2009-16 pp. 1-26.

Koch, S. F. (2017), 'User fee abolition and the demand for public health care', South African Journal of Economics 85(2), 242-258.

Koch, S. F. and Racine, J. S. (2016), 'Healthcare facility choice and user fee abolition: regression discontinuity in a multinomial choice setting', Journal of the Royal Statistical Society: Series A (Statistics in Society) 4(179), 927-950.

Kozhimannil, K. B., Abraham, J. M. and Virnig, B. A. (2012), 'National trends in health insurance coverage of pregnant and reproductive-age women, 2000 to 2009', Women's Health Issues 22(2), 135-141.

Mackenbach, J. P., Stirbu, I., Roskam, A.-J. R., Schaap, M. M., Menvielle, G., Leinsalu, M. and Kunst, A. E. (2008), 'Socioeconomic inequalities in health in 22 European countries', New England Journal of Medicine 358(23), 2468-2481.

McCoy, D. and Khosa, S. (1996), "Free health care" policies, in D. Harrison, P. Barron and J. Edwards, eds, 'South African Health Review 1996', Health Systems Trust and Henry J. Kaiser Family Foundation, pp. 157-165.

McIntyre, D., Goudge, J., Harris, B., Nxumalo, N. and Nkos, M. (2009), 'Prerequisites for National Health Insurance in South Africa: Results of a national household survey', SAMJ: South African Medical Journal 99(10), 725-729.

McIntyre, D., Thiede, M. and Birch, S. (2009), 'Access as a policy-relevant concept in low-and middle-income countries', Health Economics, Policy and Law 4(2), 179-193.

McLeod, H. (2007), 'Framework for post-retirement protection in respect of medical scheme contributions', Department of Social Development, ed. Reform of Retirement Provisions: Feasibility Studies. Pretoria.

McLeod, H. (2009a), 'Expanding health insurance coverage', National Health Insurance Policy Brief 2. Innovative Medicines. South Africa. 
McLeod, H. (2009b), 'The population for universal coverage', National Health Insurance Policy Brief 1. Innovative Medicines. South Africa.

McLeod, H. (2012), 'Myths about medical schemes', National Health Insurance Policy Brief 21. Innovative Medicines. South Africa.

Nteta, T. P., Mokgatle-Nthabu, M. and Oguntibeju, O. O. (2010), 'Utilization of the primary health care services in the Tshwane region of Gauteng province, South Africa', PloS One 5(11), 1-8.

Ntuli, M., Kwenda, P., Chitiga-Mabugu, M., Karuaihe, S., Tsoanamatsie, N. and Alaba, F. (2016), 'Gender inequalities in morbidity: A South African investigation', Studies in Economics and Econometrics 40(3), 39-63.

Rathod, S. D., Chi, B. H., Kusanthan, T., Chilopa, B., Levy, J., Sikazwe, I., Mwaba, P. and Stringer, J. S. (2014), 'Trends in all-cause mortality during the scale-up of an antiretroviral therapy programme: A cross-sectional study in Lusaka, Zambia', Bulletin of the World Health Organization 92(10), 734-741.

Ruff, B., Mzimba, M., Hendrie, S. and Broomberg, J. (2011), 'Reflections on health-care reforms in South Africa', Journal of Public Health Policy 32(1), 184-192.

South Africa Constitution (1996), Constitution of the Republic of South Africa Act, No. 108 of 1996, Government printer, South Africa, Pretoria.

StataCorp (2015), 'Stata statistical software: Release 14', College Station, TX StataCorp LP.

Statistics South Africa (2014a), 'General Household Survey 2014 [Statistical Release P0318 2015]', Pretoria: Statistics South Africa [producer], 2015. Pretoria: South African Data Archive, National Research Foundation [distributor], 2015.

Statistics South Africa (2014b), Mortality and cause of death in South Africa, 2013: Findings from death notification, Technical report, Statistics South Africa, Pretoria.

Tanaka, S. (2014), 'Does abolishing user fees lead to improved health status? Evidence from post-apartheid South Africa', American Economic Journal: Economic Policy 6(3), 282-312. 
Thiede, M., Akweongo, P., McIntyre, D., McIntyre, D. and Mooney, G. (2007), Exploring the dimensions of access, in D. McIntyre and G. Mooney, eds, 'The Economics of Health Equity', Cambridge University Press, Cambridge, UK, chapter 6, pp. 103-123.

Van den Heever, A. M. (2016), 'South Africa's universal health coverage reforms in the postapartheid period', Health Policy 120(12), 1420-1428.

Wandera, S. O., Kwagala, B. and Ntozi, J. (2015), 'Determinants of access to healthcare by older persons in Uganda: A cross-sectional study', International Journal for Equity in Health 14(1), 26. 


\section{Appendix A Descriptive statistics of Public health care facility utilisation and Medical aid coverage}

Table A.1: Descriptive statistics of Public health care facility utilisation and Medical aid coverage

\begin{tabular}{lccccc}
\hline \hline \multirow{2}{*}{ Years } & \multicolumn{2}{c}{ Public health facility } & & \multicolumn{2}{c}{ Medical aid coverage } \\
\cline { 2 - 3 } \cline { 5 - 5 } All & $\mathrm{n}$ & $\%$ & & $\mathrm{n}$ & $\%$ \\
2002 & 850,774 & 78.19 & & 174,178 & 13.68 \\
2003 & 5,669 & 5.5 & & 14,907 & 14.6 \\
2004 & 73,506 & 5.5 & & 14,018 & 14.1 \\
2005 & 85,214 & 75.8 & & 13,788 & 14.2 \\
2006 & 86,140 & 81.7 & & 11,754 & 10.9 \\
2007 & 87,140 & 80.7 & & 12,301 & 10.8 \\
2008 & 76,717 & 81.3 & & 11,765 & 11.2 \\
2009 & 73,925 & 78.9 & & 13,052 & 13.4 \\
2010 & 73,876 & 78.3 & & 14,172 & 14.8 \\
2011 & 72,167 & 78.3 & & 13,086 & 14 \\
2012 & 69,116 & 76.4 & & 14,351 & 15.7 \\
2013 & 71,263 & 76.4 & & 15,390 & 16.4 \\
2014 & 70,553 & 76.5 & 14,173 & 15.3 \\
\hline \hline
\end{tabular}

The result indicates that, in 2006, approximately $82 \%$ were more likely to prefer to seek treatment at a public health facility, when ill. From 2008, however, relatively fewer people affirmed that they would prefer to utilise public health care services in the event of illness/injury. Finally, the percentage of individuals who reported they were members of medical aid schemes remained relatively stable over the survey years. However, coverage oscillates in the latter surveys.

Table A.2: Marginal Effects for Public Health Facility Utilisation and Medical Aid Coverage

\begin{tabular}{lcccc}
\hline \hline Variables & \multicolumn{2}{c}{ Public health facility } & \multicolumn{2}{c}{ Medical aid coverage } \\
\hline 2005 & $-0.018^{* * *}$ & $(0.003)$ & -0.001 & $(0.002)$ \\
2006 & 0.004 & $(0.003)$ & -0.002 & $(0.002)$ \\
2007 & $-0.024^{* * *}$ & $(0.003)$ & 0.003 & $(0.002)$ \\
2008 & $0.008^{* *}$ & $(0.003)$ & $0.020^{* * *}$ & $(0.002)$ \\
2009 & $-0.010^{* * *}$ & $(0.003)$ & $0.018^{* * *}$ & $(0.002)$ \\
2010 & $-0.024^{* * *}$ & $(0.003)$ & $0.024^{* * *}$ & $(0.002)$ \\
2011 & $-0.017^{* * *}$ & $(0.003)$ & $0.008^{* * *}$ & $(0.002)$ \\
2012 & $-0.028^{* * *}$ & $(0.003)$ & $0.020^{* * *}$ & $(0.002)$ \\
2013 & $-0.011^{* * *}$ & $(0.003)$ & $0.026^{* * *}$ & $(0.002)$ \\
\hline
\end{tabular}


Marginal Effects for Public Health Facility Utilisation and Medical Aid Coverage: Continued

\begin{tabular}{|c|c|c|c|c|}
\hline \multirow{2}{*}{$\begin{array}{l}\text { Variables } \\
2014\end{array}$} & \multicolumn{2}{|c|}{ Public health facility } & \multicolumn{2}{|c|}{ Medical aid coverage } \\
\hline & $-0.013^{* * *}$ & $(0.003)$ & $0.020^{* * *}$ & $(0.002)$ \\
\hline Age & $0.005^{* * *}$ & $(0.000)$ & $-0.006^{* * *}$ & $(0.000)$ \\
\hline Age-squared & $-0.000^{* * *}$ & $(0.000)$ & $0.000^{* * *}$ & $(0.000)$ \\
\hline African/Black & $0.625^{* * *}$ & $(0.003)$ & $-0.473^{* * *}$ & $(0.003)$ \\
\hline Coloured & $0.510^{* * *}$ & $(0.003)$ & $-0.390^{* * *}$ & $(0.004)$ \\
\hline Indian/Asian & $0.274^{* * *}$ & $(0.006)$ & $-0.298^{* * *}$ & $(0.005)$ \\
\hline Female & $0.005^{* * *}$ & $(0.001)$ & $0.004^{* * *}$ & $(0.001)$ \\
\hline Married & $-0.070^{* * *}$ & $(0.002)$ & $0.081^{* * *}$ & $(0.002)$ \\
\hline Widow/widower & 0.001 & $(0.004)$ & $0.008^{* *}$ & $(0.003)$ \\
\hline Divorce or separated & -0.007 & $(0.005)$ & $0.017^{* * *}$ & $(0.003)$ \\
\hline Eastern Cape & $0.037^{* * *}$ & $(0.003)$ & $0.018^{* * *}$ & $(0.001)$ \\
\hline Northern Cape & $0.072^{* * *}$ & $(0.002)$ & $0.004^{* *}$ & $(0.001)$ \\
\hline Free State & $-0.063^{* * *}$ & $(0.003)$ & $0.021^{* * *}$ & $(0.002)$ \\
\hline Kwazulu/Natal & $0.054^{* * *}$ & $(0.003)$ & $0.019^{* * *}$ & $(0.002)$ \\
\hline North-West & $-0.046^{* * *}$ & $(0.003)$ & $0.047^{* * *}$ & $(0.002)$ \\
\hline Gauteng & $-0.013^{* * *}$ & $(0.003)$ & $0.031^{* * *}$ & $(0.002)$ \\
\hline Mpumalanga & $-0.050^{* * *}$ & $(0.003)$ & $0.048^{* * *}$ & $(0.002)$ \\
\hline Limpopo & $0.042^{* * *}$ & $(0.003)$ & $0.043^{* * *}$ & $(0.002)$ \\
\hline Less than diploma/certificate & $-0.043^{* * *}$ & $(0.002)$ & $0.039^{* * *}$ & $(0.001)$ \\
\hline Diploma/certificate & $-0.397^{* * *}$ & $(0.005)$ & $0.338^{* * *}$ & $(0.005)$ \\
\hline Honours/degree & $-0.542^{* * *}$ & $(0.006)$ & $0.484^{* * *}$ & $(0.007)$ \\
\hline Postgraduate degree & $-0.594^{* * *}$ & $(0.018)$ & $0.468^{* * *}$ & $(0.028)$ \\
\hline Employment status & $-0.074^{* * *}$ & $(0.002)$ & $0.047^{* * *}$ & $(0.001)$ \\
\hline Metropolitan status & $-0.150^{* * *}$ & $(0.002)$ & $0.109^{* * *}$ & $(0.001)$ \\
\hline Observation & $1,064,453$ & & $1,064,453$ & \\
\hline$R^{2}$ & 0.25 & & 0.29 & \\
\hline
\end{tabular}

Standard errors in parentheses

${ }^{*} p<0.05,{ }^{* *} p<0.01,{ }^{* *} p<0.001$ 